\title{
Management of Mobile Phone Community in Jordan
}

\author{
Monther Kanan ${ }^{1}$, Ziad Al-Asmer ${ }^{2}$ \\ ${ }^{1}$ Department of Mechantoncis Engineering, Faculty of Engineering Technology, Al Balq’a Applied University, Amman, Jordan; ${ }^{2}$ De- \\ partment of Computer Engineering, Faculty of Engineering Technology, Al Balq’a Applied University, Amman, Jordan. \\ Email: \{kananmonther, Ziad_alasmer\}@yahoo.com
}

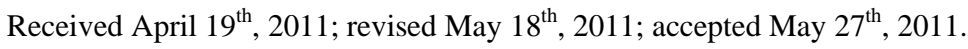

\begin{abstract}
The need of a fast and global communication service has increased the competition among mobile phone companies. Therefore, those companies started adapting new methods to satisfy the needs of their customers. The Information Technology system proposed in this work is believed to provide an effective trading and managing tool for mobile's community in Jordan.
\end{abstract}

Keywords: System Management, SMS Mobile’s Serves, Server Replay the SMS

\section{Introduction}

The need of a fast and reliable global communication service has increased the competition among mobile companies. For the past few decades, communication technology has been widely and continuously developed. Worldwide, mobile companies needed to develop new methods to keep on providing the quality service expected by their customers. Information Technology (IT) solutions can reduce time and cost for companies by automating the systems connecting the companies with different marketing stores using Internet services.

The proposed IT solution is integrated with a server side application. The server side application will be responsible for managing companies marketing stores, products, product's type, offers and announcements. The Short Message Service (SMS) will be used to query about what product is needed from specific company thought the system.

The system proposed in this work is composed of different parts, which are not found in the current systems used by the mobile companies in the Hashemite Kingdom of Jordan. It joins all different companies through one system making it easy for the customer to find the product of interest.

The idea of this work started after conducting a questioner that covers the different aspects of mobile's trading. The questioner and IT system developed for this work could be conducted and applied for different types of companies, agencies and organizations. The IT solution can be applied with some variations in the system specification based on the company's type. Nowadays, Internet services and mobile phone services are the most widely used communication technology. Therefore, the proposed system is based on using those services, which will provide convenience to the customers in locating their product of interest. The proposed system allows the user to search for the product of interest using the World Wide Web (WEB) and the Wireless Application Protocol (WAP) pages. This requires having access to both or either one of those two services. In general the system provides the user with the information of interest without the need of having Internet access. The user sends a special coded SMS to the server; in return the server reads, analyzes and replies to the sender with the required information as an SMS.

\section{Business Context}

When looking at the current systems found in mobile companies trading process, it is noticed that each company has its own website, and sometimes different marketing stores have their own website too.

When a potential customer wants to buy a specific product, usually the best solution is going to the nearest store and asking about the product of interest, or sometimes consulting a friend about the best place to find that product. This process is timing consuming and may not lead the potential customers in finding the product of 
interest. However, if the search was done using an automated system it is believed that the customer will reach to the product of interest more conveniently. Moreover, it increases trading performance, it saves time, and it provides more connections between the companies and their marketing stores.

\section{Product Function}

The proposed system is expected to cover the mobile's trading operation from selling, buying and announcing more accurately than the current system. It starts when a potential customer wants to buy a specific product from a nearby store or company. The proposed system will provide the store or company with an effective tool to locate the customer's product of interest.

The proposed system allows the system user to search for the product of interest by using either the WEB or WAP services. This will require the user to join one or both of these services. The main function of this system is that it provides the means to search for a product without the need to have internet access. It allows for the search in the database by only sending an SMS to the server with a special code message. In return the server reads and analyzes the message, and reply to the same mobile phone that initiated the request with the results of the query.

\section{Data Collection}

The main task of the proposed work directs the issues concerning the mobile sales manager, customers, service centers and related governmental agencies. The first step taken was closely examining functionality of the existing systems and determining their weakness. After that, a questionnaire was conducted. The questionnaire carried out the demands, suggestions and opinions of mobile sales managers in general. The feedback received from these questioners was used to construct the proposed system.

The objects in this work are the mobile stores, mobile companies and customers; they are the kernels of any mobile market system.

\subsection{Questionnaire Approaches}

Similar systems to the proposed system exist. Such system is the function of mobile management software products. Even though the presented work serves and solves most encountered problems in the mobile market, it is difficult to use in our country because of the following,

- They don't cover the problem of safety in our country.

- They cannot serve the users, unless they are connected to the Internet.
- They do not cover services at our country.

For these reasons, our society demands were divided for analysis based on questions classified into four approaches.

First approach

The existence of personal computers (PC) and commutation facilities, and their application in mobile's market.

This approach have been covered by the following questions,

Q1. The presence necessity of PCs, network and Internet in the company.

Q2. The presence of PC in the store.

Q3. The presence of Internet in the store.

\section{Second approach}

The necessity of software developing.

Q4. The presence of an application, which serves mobile stores and service centers.

Q5. The necessity of an application, which serves the customer.

Q6. The necessity of an application, which serves government and related agencies in mobile market.

\section{Third approach}

Comparing the proposed system with the existing one using the following,

Q7. Orientation.

Q8. Market compatibility.

Q9. Country agreement.

Q10. Simplicity.

\section{Fourth approach}

Recommendations. The work presented in this project is limited to the sales managers' recommendations.

\subsection{Questionnaire Formation}

All questions presented on the questionnaire could be answered by one of the following,

1) Always

2) Often

3) Sometimes

4) Rarely

\subsection{Results and Data Analysis}

\section{First approach}

Results (see Table 1)

Table 1. Questioners results of the first approach.

\begin{tabular}{lcccc}
\hline \multicolumn{1}{c}{ Question } & Always & Often & Sometimes & Rarely \\
\hline $\begin{array}{l}\text { Q1. The presence necessity } \\
\text { of network and Internet in the }\end{array}$ & $70 \%$ & $14 \%$ & $10 \%$ & $6 \%$ \\
company & & & & \\
$\begin{array}{l}\text { Q2. The presence of PC in } \\
\text { the store }\end{array}$ & $42 \%$ & $23 \%$ & $15 \%$ & $18 \%$ \\
$\begin{array}{l}\text { Q3. The presence of Internet } \\
\text { access in the store }\end{array}$ & $23.2 \%$ & $3.2 \%$ & $18 \%$ & $61 \%$ \\
\hline
\end{tabular}


Personal computers (PC's) takes a great place in our daily activities and so does the Internet access. The first approach had covered the presence of PC according to social and material conditions of mobile sales manager, the presence of Internet service according to geographical places and life conditions.

\section{Analysis}

The result shows that the existed system does not hold the connectivity and simplicity. It was found that a large percent, 61\%, of the stores do not have Internet access. Also, the results indicated that $70 \%$ of the companies prefer always using computers and network connections. $10 \%$ indicated that they could sometimes use such connections, while $6 \%$ showed that they would rarely use such connection.

The developed system would be a perfect solution for the stores to which will allow them to use internet through sending SMS to the server without connecting to internet.

\section{Second approach}

\section{Results (see Table 2)}

Analysis

The advantages of the proposed system are discussed and presented according to the feedback received from mobile stores, service centers and customers,

1) High-level security while selecting and traveling form one filed to another.

2) Internet disconnection problem could be solved by sending an SMS to the server.

Internet dependency, which means that the user must have the skills to use a PC and surf the Internet. To avoid this issue which is a problem to lot of the users, sending an SMS requesting a product could be the solution.

\section{Third approach}

Results (see Table 3)

Table 2. Questioners results of the second approach.

\begin{tabular}{lcccc}
\hline \multicolumn{1}{c}{ Question } & Always & Often & Sometimes & Rarely \\
\hline $\begin{array}{l}\text { Q4. The presence of an } \\
\text { application which serves mobile } \\
\text { stores and serves centers }\end{array}$ & $21.9 \%$ & $25 \%$ & $47.1 \%$ & $5 \%$ \\
$\begin{array}{l}\text { Q5. The necessity of an } \\
\text { application which serves the }\end{array}$ & $45 \%$ & $27.4 \%$ & $18 \%$ & $9.6 \%$ \\
$\begin{array}{l}\text { customer } \\
\begin{array}{l}\text { Q6. The necessity of an } \\
\text { application which serves gov- } \\
\text { ernment and related agencies in } \\
\text { mobile market }\end{array}\end{array}$ & $90 \%$ & $7 \%$ & $2.2 \%$ & $1.8 \%$ \\
\hline
\end{tabular}

Table 3. Questioners results of the third approach.

\begin{tabular}{lcccc}
\hline \multicolumn{1}{c}{ Question } & Always & Often & Sometimes & Rarely \\
\hline Q7.Oriantation & $10.9 \%$ & $18.7 \%$ & $29.6 \%$ & $39.5 \%$ \\
Q8. Market compatibility & $29.6 \%$ & $19.7 \%$ & $20.8 \%$ & $20.6 \%$ \\
Q9. Country agreement & $24 \%$ & $45 \%$ & $23 \%$ & $7.7 \%$ \\
Q10. Simplicity & $15.4 \%$ & $28.5 \%$ & $28.6 \%$ & $26 \%$ \\
\hline
\end{tabular}

\section{Analysis}

The proposed system provides the following features,

1) It includes integrated database system for the companies, stores and customers.

2) Connection with companies, stores and customers via SMS and site.

3) Flexible and simple user interface for data entry, which eliminates errors during data entry for companies and stores.

Supplemented features could be recommendation for producing the next generation of suggested software.

\section{User Problem Statement}

The users of the current system face several problems, such problems include,

- Difficulty and lack of communication between mobile stores, service centers, and companies.

- Difficulty and lack of communication between stores and customers.

- The delay in finding the product of interest, which is needed by the customer.

- Lack of data integrity and security.

- Waste of time.

\section{Proposed System}

\subsection{Description of the Proposed System}

The system proposed in this work provides the company, store and their customers with a trading Internet website. It is also provides services by sending an SMS to a server inquiring about a product of interest. This will result in cutting down, cost, time and wasted efforts.

The system is divided into two main parts,

1) Server side (accessed by the administrator and authorized companies)

2) Clients Side (used by stores and customers).

The administrator will use the server to,

- Store the database of the companies, stores, customers, announcements, offers, products and product's type.

- Control and facilitate the distribution of customers and stores among different regions of the country.

Make statistics study to show the store, the products and product's type distribution within a certain area.

\subsection{Objectives of the Proposed System}

- Facilitate the communication between company and store

- Facilitate the communication between customer and store.

- Facilitate the communication between customer and company.

- Organize workflow. 
- Save effort, time and human resources.

- Eliminate paper work.

- Achieve data integrity.

- Achieve high level of security.

- Retrieve data efficiently.

- Reduce inputs faults.

- Higher means of control.

- Simple process and steps to follow for each process.

- Electronic system so it will be fast and accurate system.

\section{Modeling}

\subsection{Database Modeling}

Database is the data structure used for storing organized information. A database is typically made up of many linked tables and their rows and columns [1,2].

Structured query language (SQL) [3] server enterprise manager is a graphical tool that allows for easy, enterprise-wide configuration and management of Microsoft SQL Server and SQL Server objects [4]. SQL Server enterprise manager can be used to,

- Manage logins, permissions, and users.

- Manage devices and databases.
- Back up databases and transaction logs.

- Manage tables, views, stored procedures, triggers, indexes, rules, defaults, and user-defined data types.

The Database modeling is a modeling language, which is based on lines connecting tables with each other by foreign keys. Figure 1 shows the database modeling of the proposed system. It shows all the different tables and connection lines used [3].

\subsection{Use Case Modeling}

The Use Case model is a unified modeling language (UML) notation. Lines connecting actors with use cases are bidirectional associations, which represent the interaction between the actor and the use case.

The dashed lines between use cases are dependencies or instantiations. They represent either an extension or inclusion that shows the relation between the connected use cases [4,5]. Figure 2 shows the use case model used in the system proposed in this work.

\section{Conclusions and Future Work}

It is believed that the proposed system will save a lot of time, effort and overhead costs. It will achieve data

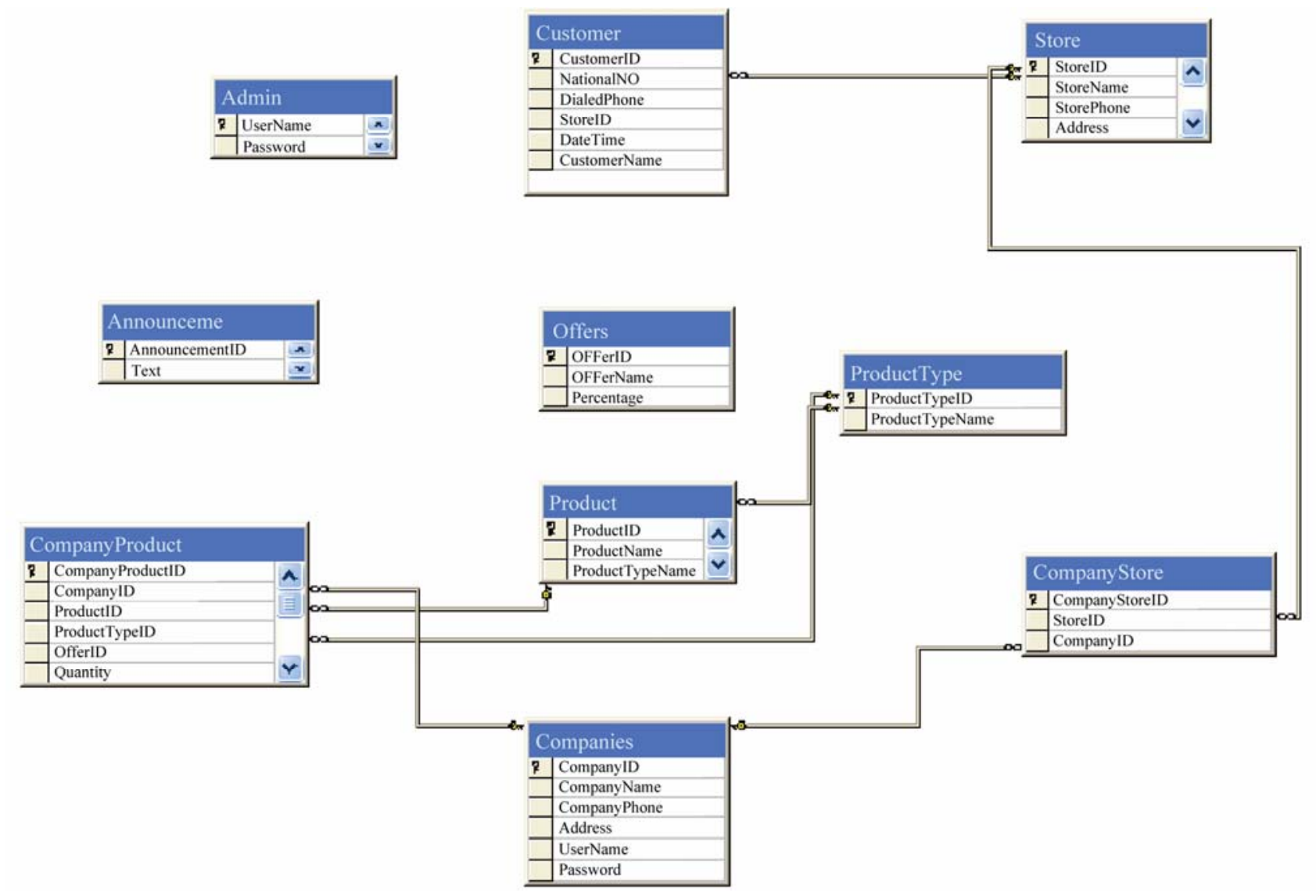

Figure 1. Data Base modeling for the work. 


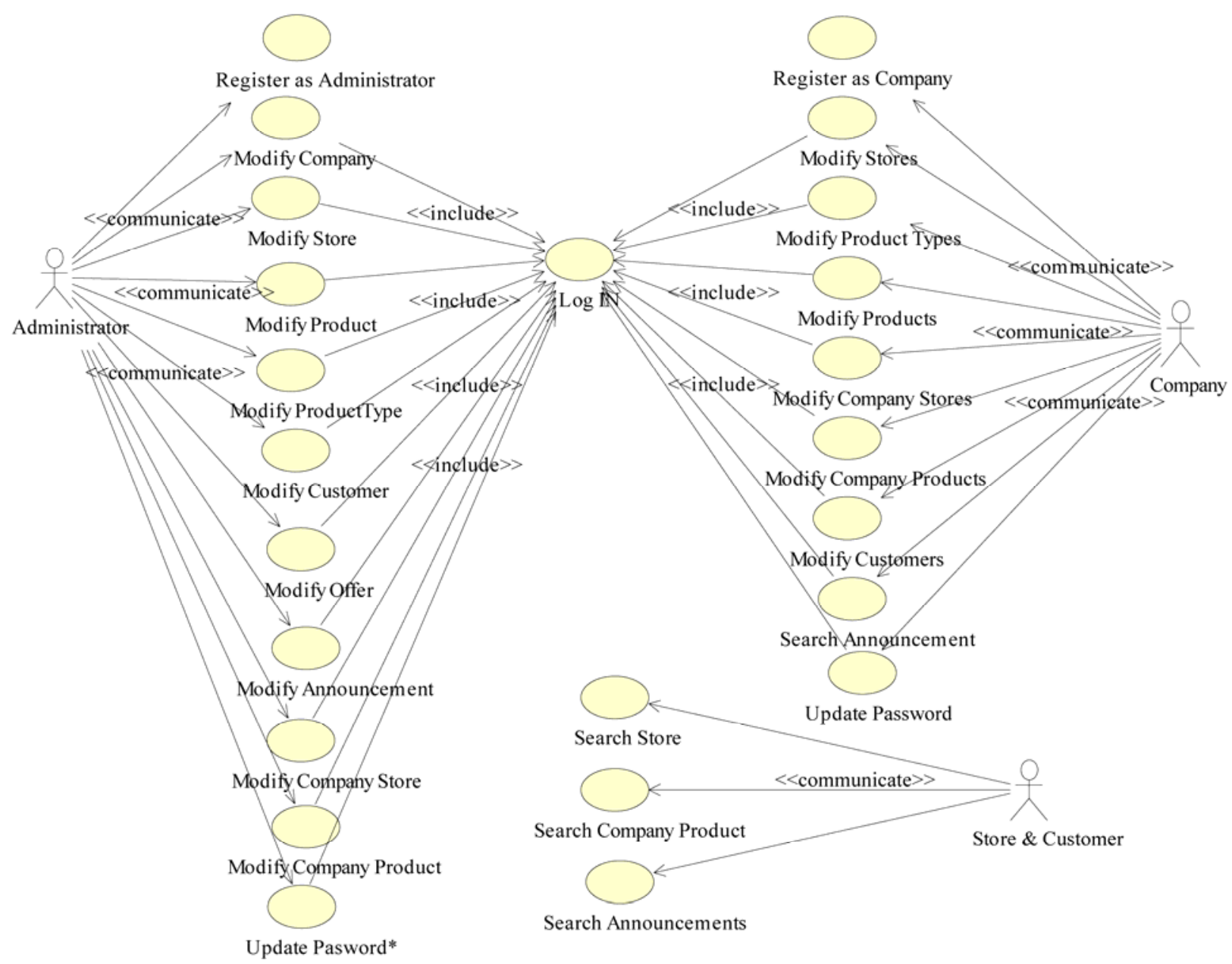

Figure 2. Use Case model.

integrity; replace the boring long procedures with a more flexible and secure one. It should be taken into account that,

- The system will constantly undergo changes and updates to accommodate the pressure and the navigation of the program and increasing system users.

- The system should be integrated with a WAP application. This will ease the search of a product of interest by using SMS from mobiles and handheld PCs.

One of the key benefits of such a system is that it provides the stores and companies with the necessary statistic results of the trading process. This could be an effective tool for day-by-day improvement to compete with the different companies in this country and in some cases, the competition with out of country companies.

Some of the future work recommend could include,

- New methods to allow the server to accept analyze and reply to calls.

- The applications of the SMS service may develop allow the store to request specific charging card numbers based on type and amount.
- Using the SMS service for activating and requesting different features on the mobile phone.

Applying the proposed system will increase the companies and stores trading process resulting in more profit, while in the same time saving the customer time and money.

\section{Recommendations}

The system proposed in this work is recommended for the different sectors and agencies in our community. It could be used to connect the different branches of an organization whether it is governmental or is the privately owned.

For its application in the mobile companies' area, the current system will be a more effective tool if each mobile company had its own trading website. This will increase the database of the system and provide the customers and marketing store owners with a wider selection of products and services.

All different companies, agencies and institutes that are still depending on obsolete methods such as paper 
filing should start considering such systems for all the benefits presented in this work. Conducting such a method is believed to improve the trading performance, which will have a positive effect on our economy.

\section{REFERENCES}

[1] Era soft (Computerized Solutions for your Business), “SQL Lecture 1," 5 May 2007. http://www.erasoft.edu.pk/

[2] Online Help for Microsoft SQL Enterprise Manager, Microsoft Corporation, Version: 7.0.
[3] E. S. Zhou, C. X. Xu, H. Wu, J. Zhang, Y. H. Lin, J. Q. Wang and J. Gray, "E-R Modeler: A Database Modeling Toolkit," Barrett Bryant Department of Computer and Information Sciences, University of Alabama at Birmingham, Birmingham, 2-3 April 2004.

[4] Terry Quatrani, Visual Modeling with Rational Rose 2000 and UML, Addison-Wesley Professional, 27 October 1999.

[5] E. F. Codd, “A Relational Model of Data for Large Shared Data Banks," Communications of the ACM, Vol. 13, No. 6, 1970, pp. 377-387. doi:10.1145/362384.362685 